\title{
Current Status of Complementary Therapies Provided by Hospice Palliative Care in South Korea
}

\author{
Sinyoung Kwon, A.P.N., Ph.D., Jihye Bak, A.P.N.* and So-Hi Kwon, A.P.N., Ph.D. ${ }^{\dagger}$ \\ Department of Nursing, Gangdong University, Eumseong, *Regional Hospice Center, Korea Cancer Hospital, Korea Institute of \\ Radiological and Medical Science, Seoul, ${ }^{\dagger}$ College of Nursing, Kyungpook National University, Daegu, Korea
}

Purpose: The aim of this study was to investigatecomplementary therapiesprovided at hospice palliative care facilities in South Koreaas designated by the Ministry of Health and Welfare. Methods: The survey was conducted via e-mail from September 2 to September 23, 2020, with responsesfrom 109 therapists and 59 managers from 55 different hospice care facilities. Results: Hospices provided an average of 3.67 different types of therapies, ranging from 1 to 7 different types. The most common types of therapies were horticultural therapy (81.4\%), music therapy (79.7\%), art therapy (76.3\%), and aromatherapy (57.6\%). The average frequency of sessions was once a week, the median duration was 60 minutes. Most therapists (96.3\%) had qualifications, but the certification-issuing organizations and training intensiveness varied greatly. None of the therapists were employed on a full-time basis, and their average monthly income was KRW 270,000. Therapists and managers gave average scores of 8.90 and 8.38 out of 10 , respectively, regarding the positive impact of complementary therapies on patients. Conclusion: In order for patients and their families to benefit from complementary therapiesat hospice care facilities, in addition tobetter terms of employment for therapists, evidence-based guidelines for different types of therapies are needed so that therapy sessions can be conducted according to the theoretical underpinnings and characteristics of the type of therapy. It is expected that the results of this study will be used for policy-making in support of therapy as an essential hospice service.

Key Words: Palliative care, Hospice care, Complementary therapies
Received December 2, 2020

Revised April 23, 2021

Accepted April 28, 2021

\section{INTRODUCTION}

Over the past decade, the number of inpatient hospice care facilities in South Korea has increased steadily from 282 beds in 19 facilities in 2008 to 1,403 beds in 87 facilities as of $\mathrm{Au}^{-}$ gust 2020 [1]. Hospice palliative care provides holistic and integrated services with interdisciplinary teams of doctors, nurses, social workers, therapists, clergy, and volunteers to alleviate the physical, psychosocial, and spiritual distress of end-stage cancer patients and their families [2]. In addition to conventional Western medicine, hospice palliative care includes a more diverse assortment of complementary therapies than other treatment methods since it emphasizes multi-dimensional, holistic care $[3,4]$. Research on the effects of complementary medicine proved that music $[5,6]$, art $[7,8]$, horticulture [9], and aroma [10] therapies not only helped relieve mental distress in terminal cancer patients and their families, but also improved patients' physical symptoms and quality of life. A meta-analysis of 31 studies on the impact of music therapy on hospice palliative care patients showed that music therapy

This is an Open Access article distributed under the terms of the Creative Commons Attribution Non-Commercial License (http://creativecommons.org/licenses/by-nc/4.0/) which permits unrestricted non-commercial use, distribution, and reproduction in any medium, provided the original work is properly cited. 
had a medium-level effect on improving psychological symptoms such as depression, tension, anxiety, and fatigue, as well as physiological symptoms. The effects were significant when patients participated six times or more in therapy sessions that used pre-recorded music [6]. Art therapies varied in methodology and duration, including activities such as book decorating, drawing, coloring, and clay art, and they had a mediumlevel impact on anxiety, depression, fatigue, and quality of life. Individual therapies had significantly greater effects than group therapies [8]. As such, existing studies confirm that the various complementary therapies provided in hospice palliative care are helpful and can provide a basis for improving the quality of care.

In South Korea, labor and material costs for complementary therapies such as horticulture, art, and music therapy offered to terminal cancer patients and their families are included in the per diem payments of hospice health insurance. Moreover, the Korean Ministry of Health and Welfare quality assessment indicators of certified hospice agencies include the offering of complementary therapies [11,12]. However, the assessment only measures quantitative indicators, such as the number of sessions provided, without making a qualitative assessment of therapy content or session leaders, making it difficult to discern whether programs are offered based on evidence of their efficacy or whether they are successful at improving the quality of life of patients and their family members. This is probably because a very wide range of therapies with different theoretical backgrounds, goals pertaining to symptom alleviation, and frequencies and methods of intervention for effective treatment are collectively categorized as "complementary therapies", and the value of each type of therapy is not assessed on scientific grounds. Complementary therapies are also undervalued as additional treatments based on the choices of patients and their families, which makes it difficult to design and offer various types of therapies in a way that maximizes their effects in terms of treatment. In order to develop a more constructive strategy for the implementation of complementary therapies, it would be necessary to understand the status of complementary therapies currently offered by certified hospice agencies.

Against this background, we conducted this study to examine the status of complementary therapies currently provided by inpatient hospice agencies, the qualifications and employment statuses of therapists who conduct complementary therapies, and the beliefs of program coordinators and therapists regarding the effectiveness of complementary therapies.

\section{METHODS}

\section{Study design}

The goal of this cross-sectional study was to examine the status of complementary therapies offered by inpatient hospice care facilities in South Korea, as well as the employment status of therapists and their beliefs regarding complementary therapies.

\section{Participants}

The participants in this study were complementary therapy managers and therapists who had worked for 1 year or longer at one of 72 certified hospice care agencies nationwide designated by the Korean Ministry of Health and Welfare, which were identified using the webpage of the Central Hospice Center of the National Cancer Center. Fifteen of the 87 certified hospice care agencies were excluded as they were shut down due to the coronavirus disease 2019 (COVID-19) pandemic as of August 2020. In total, 59 managers and 109 therapists from 55 hospice agencies nationwide participated in the study, with an institutional participation rate of $76.4 \%$.

\section{Study tools}

Unique surveys were developed for managers and for therapists in order to identify the current status of complementary therapies. The survey content was reviewed for validity by a team of 10 experts including a nursing professor, a doctor at a certified hospice facility, two certified hospice nurses, a social worker, and five therapists. The surveys were conducted after being revised and modified according to the experts' feedback. The survey for complementary therapy program managers included questions on the general characteristics and occupation types of the managers, the types of therapies provided by their institutions, compensation for therapists, and the goals, frequency, duration, and size of each therapy session. The survey for therapists included questions on their education and qualifications, employment type, compensation, and the goals, 
frequency, duration, and size of each therapy session.

Both surveys included questions to identify participants' beliefs regarding complementary therapies and what was needed to improve the efficacy of such therapies. Four questions were asked to determine participants' beliefs regarding the necessity of complementary therapy in hospice palliative care, the impact of complementary therapy on patients and families, and how complementary therapies helped patients and families. Participants' beliefs regarding the necessity of complementary therapy in hospice palliative care were rated using a visual analogue scale ranging from 0 to 10 , with 0 indicating "not necessary at all" and 10 indicating "extremely necessary". Participants' beliefs regarding the impact of complementary therapy in hospice palliative care on patients and family members were also rated using a visual analogue scale ranging from 0 to 10 , with 0 indicating "very negative" and 10 indicating "very positive". Patients and family members were also asked how complementary therapies helped them by selecting multiple responses from the following options: "palliating physical symptoms", "psycho-emotional support", "restoration of social functions", "promoting spiritual well-being", "restoration of family relationship", and "acceptance of death". Participants were asked to choose multiple responses that corresponded to their beliefs about how to improve the efficacy of complementary therapies from the following items: "expanding policy support at the government level", "strengthening the individual expertise of therapists", "managing and standardizing therapist qualifications", "improving public awareness of the need for various therapies in hospice", "standardizing complementary therapies", "strengthening education and training programs for hospice therapists", and "providing physical and environmental support for complementary therapy from institutions".

\section{Data collection}

The purposeand method of this study were approved by the institutional review board of $\mathrm{K}$ hospital (IRB No.: KIRAMS 2020-08-005).

Data collection was conducted between September 2 and September 23, 2020. The researchers called all 87 certified hospice care providers in South Korea using the contact list available on the Central Hospice Center of the National Cancer Center webpage and explained the purpose, goals, meth- ods, and privacy protection policy of the study. Of the 87 hos- $^{-}$ pice care centers, 15 were shut down due to the COVID-19 pandemic and 17 additional centers declined to participate after having temporarily paused complementary therapy services due to the COVID-19 pandemic.

The remaining 55 institutions provided the researchers with lists of complementary therapy program managers and therapists who agreed to have their contact information provided after they were given a brief description of the study and consented to have their contact information shared with the researchers. The researchers explained the purpose, goals, method, and privacy policies of the study to potential participants over the phone using the contact lists received from hospice care centers and sent consent forms and surveys via email to the 168 people who agreed to participate. All 59 managers and 109 therapists returned their completed surveys and consent forms. The researchers confirmed any missing information with participants over the phone.

\section{Data analysis}

The collected data were analyzed using SPSS version 12.0 (SPSS Inc., Chicago, IL, USA). The general characteristics of the participants, the types of therapies, number of therapy participants, and frequency of sessions were analyzed in terms of frequency, percentage, average, and standard deviation. The necessity of complementary therapy and differences in beliefs between managers and therapists on the impact of therapies on patients and their families were verified using the $t$-test.

\section{RESULTS}

\section{The characteristics of complementary therapy managers and the status of complementary therapy management}

The background disciplines of hospice therapy managers in certified hospice institutions were social work (83.1\%) and nursing (16.9\%). Of the managers with nursing backgrounds, $50 \%$ held the position of an advanced practice nurse. Most of the institutions were general hospitals (59.3\%), followed by tertiary hospitals $(22.0 \%)$, clinics (10.2\%), and primary hospitals $(8.5 \%)$. The average amount of total clinical experience 
among managers was 112.74 months (9 years, 5 months) and their average amount of hospice experience was 47.81 months (4 years) (Table 1$)$.

Institutions conducted an average of 3.67 therapy programs (range, 1 7). In terms of types of therapies, $81.4 \%$ of institutions conducted horticulture therapy, followed by music therapy (79.7\%), art therapy (76.3\%), and aromatherapy (57.6\%). Tea ceremonies $(22.0 \%)$, crafting therapy $(15.3 \%)$, body movement/ exercise therapy (10.2\%), foot massages (8.5\%), and cooking $(5.1 \%)$ were also common therapies conducted by hospice care facilities. In terms of financial compensation, $79.7 \%$ of facilities provided monthly wages to therapists and $15.3 \%$ paid therapists per session. The average compensation per session was KRW 55,000 and the average time spent per week on work related to managing complementary therapies was 177.97 minutes, with a median time of 120 minutes (Table 1).

Table 1. Characteristics of Hospice Therapy Managers ( $N=59)$.

\begin{tabular}{|c|c|c|c|c|}
\hline Characteristics & Categories & $\mathrm{n}(\%)$ & Mean $\pm S D$ & Median (range) \\
\hline \multirow[t]{2}{*}{ Discipline } & Nurse & $10(16.9)$ & & \\
\hline & Social worker & $49(83.1)$ & & \\
\hline \multirow[t]{3}{*}{ Position, if nurse } & Head nurse & $2(20.0)$ & & \\
\hline & Team leader & $3(30.0)$ & & \\
\hline & Advanced practice nurse & $5(50.0)$ & & \\
\hline \multirow[t]{4}{*}{ Hospital type } & Tertiary hospital & $13(22.0)$ & & \\
\hline & General hospital & 35 (59.3) & & \\
\hline & Primary hospital & $5(8.5)$ & & \\
\hline & Clinic & $6(10.2)$ & & \\
\hline Clinical experience (mo) & & & $112.74 \pm 98.06$ & $87(0 \sim 420)$ \\
\hline Hospice experience (mo) & & & $47.81 \pm 44.38$ & 33 (0 207) \\
\hline \multirow{3}{*}{$\begin{array}{l}\text { Number of different types of } \\
\text { therapies conducted }\end{array}$} & $1 \sim 2$ & $8(13.6)$ & $3.67 \pm 1.22$ & $4(1 \sim 7)$ \\
\hline & $3 \sim 4$ & $39(66.1)$ & & \\
\hline & $\geq 5$ & $12(20.3)$ & & \\
\hline \multirow[t]{14}{*}{ Type of therapies conducted } & Horticultural & $48(81.4)$ & & \\
\hline & Music & $47(79.7)$ & & \\
\hline & Art & 45 (76.3) & & \\
\hline & Aroma & $34(57.6)$ & & \\
\hline & Tea ceremony & $13(22.0)$ & & \\
\hline & Handicraft & $9(15.3)$ & & \\
\hline & Body movement/exercise & $6(10.2)$ & & \\
\hline & Foot massage & $5(8.5)$ & & \\
\hline & Calligraphy & $2(3.4)$ & & \\
\hline & Cooking & $3(3.4)$ & & \\
\hline & Reading & $2(3.4)$ & & \\
\hline & Laugh therapy & $1(1.7)$ & & \\
\hline & Psychotherapy & $1(1.7)$ & & \\
\hline & Color & $1(1.7)$ & & \\
\hline \multirow[t]{4}{*}{ Financial compensation oftherapists } & None & $5(8.5)$ & & \\
\hline & Monthly wage & $47(79.7)$ & & \\
\hline & Weekly wage & $2(3.4)$ & & \\
\hline & Payment by session & $9(15.3)$ & & \\
\hline $\begin{array}{l}\text { Compensation per session } \\
(1,000 \mathrm{KRW})\end{array}$ & & & $55.64 \pm 188.88$ & $50(0 \sim 100)$ \\
\hline $\begin{array}{l}\text { Minutes per week for therapy } \\
\text { management }\end{array}$ & & & $177.97 \pm 148.27$ & $120(20 \sim 600)$ \\
\hline
\end{tabular}


In total, $60 \% \sim 85.7 \%$ of therapies targeted patients and their family members, and $40.0 \%$ of foot massages, $36.4 \%$ of tea ceremonies, $25.5 \%$ of horticulture therapies, and $22.2 \%$ of crafting therapies were offered to hospice workers as well. The frequency of sessions varied by type, with a range of 3.64 to 7.15 sessions per month. However, the median frequency of sessions was 4 sessions per month across all therapy types. The median duration of sessions was 60 minutes across all therapy types except for body movement/exercise therapy. The median number of participants per session for body movement/exercise therapy was 3 , while aromatherapy and foot massages had the highest number of participants $(n=8)$ (Table 2).

\section{The characteristics of therapists and types of therapies conducted}

In total, $99.1 \%$ of therapists were women and their average age was 48.05 years. The largest proportion (40.4\%) of therapists were Protestant, and $46.7 \%$ of therapists had a master' s degree, while $35.8 \%$ had a bachelor's degree and $8.3 \%$ had a doctoral degree. Therapists had an average amount of total clinical experience of 111.46 months (9 years, 4 months) and an average amount of hospice experience of 58.04 months (3 years, 4 months). Almost all (96.3\%) of therapists held certificates of qualification for specific therapies issued by either professional associations (58.1\%), academic societies (15.2\%), universities or institutions of continuing education (12.3\%), or government departments and their affiliated offices (6.7\%). The number of hours required by certification programs largely varied, ranging from 20 hours to 3,080 hours, with an average of 555.12 hours and a median of 300 hours. In total, $48.6 \%$ of therapists had completed a standard hospice curriculum (Table 3).

A majority (64.2\%) of therapists worked at general hospitals and were permanent employees $(74.3 \%)$, while $11.0 \%$ worked on a volunteer basis. In total, $87.2 \%$ of therapists worked part-time for an average of 145.94 minutes weekly, with a median of 90 minutes. Monthly financial compensation was received by $74.3 \%$ of therapists, and $13.8 \%$ of therapists were paid per session, while $8.3 \%$ did not receive any compensation. The compensation per session ranged from KRW 10,000 to KRW 150,000, with a median of KRW 50,000, and therapists' average monthly income was KRW 270,000 (median, KRW

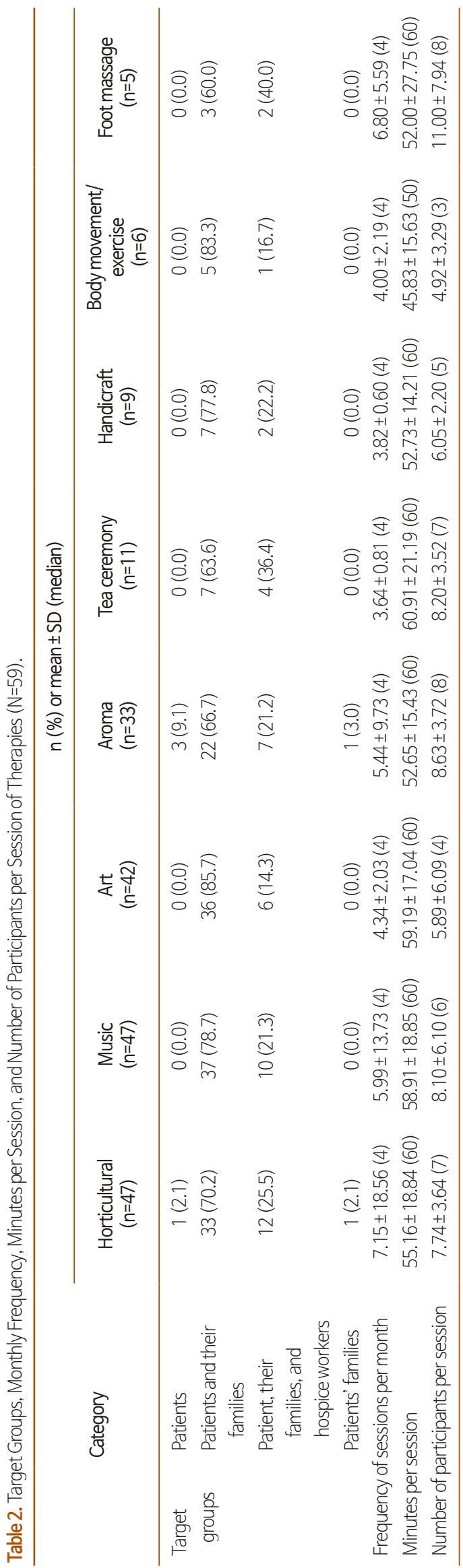

http://www.e-jhpc.org 
Table 3. Characteristics of Therapists ( $N=109)$.

\begin{tabular}{|c|c|c|c|c|}
\hline Characteristics & Categories & $\mathrm{n}(\%)$ & Mean \pm SD & Median (range) \\
\hline \multirow[t]{2}{*}{ Sex } & Male & $1(0.9)$ & & \\
\hline & Female & $108(99.1)$ & & \\
\hline Age (yr) & & & $48.05 \pm 10.30$ & $48(23 \sim 73)$ \\
\hline \multirow[t]{5}{*}{ Religion } & Protestant & $44(40.4)$ & & \\
\hline & Catholic & $27(24.8)$ & & \\
\hline & Buddhist & $17(15.6)$ & & \\
\hline & None & $20(18.3)$ & & \\
\hline & Other & $1(0.9)$ & & \\
\hline \multirow[t]{4}{*}{ Education } & Bachelor's & $39(35.8)$ & & \\
\hline & Master's & $51(46.7)$ & & \\
\hline & $\mathrm{PhD}$ & $9(8.3)$ & & \\
\hline & Other & $10(9.2)$ & & \\
\hline \multirow[t]{2}{*}{ A certificate of qualification for therapy } & Yes & $105(96.3)$ & & \\
\hline & No & $4(3.7)$ & & \\
\hline \multirow[t]{5}{*}{ Certification issuing agency $(n=105)$} & $\begin{array}{l}\text { Government department or } \\
\text { affiliated office }\end{array}$ & $7(6.7)$ & & \\
\hline & Academic society & $19(15.2)$ & & \\
\hline & Association & $61(58.1)$ & & \\
\hline & $\begin{array}{l}\text { University or institution of } \\
\text { lifelong education }\end{array}$ & $13(12.3)$ & & \\
\hline & Other & $5(4.7)$ & & \\
\hline Hours of the certification program $(n=84)$ & & & $555.12 \pm 633.66$ & $300(20 \sim 3,080)$ \\
\hline Clinical experience $(\mathrm{mo})(\mathrm{n}=106)$ & & & $111.46 \pm 127.98$ & $78.5(6 \sim 1,188)$ \\
\hline Hospice experience (mo) (n=108) & & & $58.04 \pm 79.85$ & 40 (1 753) \\
\hline \multirow{2}{*}{$\begin{array}{l}\text { Completion of the standard } \\
\text { curriculum for hospice }\end{array}$} & Completed & $53(48.6)$ & & \\
\hline & Not completed & $56(51.4)$ & & \\
\hline \multirow{5}{*}{$\begin{array}{l}\text { Type of hospital where the participant } \\
\text { worked* }\end{array}$} & Tertiary hospital & $20(18.3)$ & & \\
\hline & General hospital & $70(64.2)$ & & \\
\hline & Primaryhospital & $12(11.4)$ & & \\
\hline & Clinic & $10(9.5)$ & & \\
\hline & Long-term care hospital & $5(4.6)$ & & \\
\hline \multirow[t]{4}{*}{ Type of employment } & Permanent employment & $0(0.00)$ & & \\
\hline & Contingent employment & $81(74.3)$ & & \\
\hline & Volunteer & $12(11.0)$ & & \\
\hline & Other & $16(14.7)$ & & \\
\hline \multirow[t]{3}{*}{ Type of work } & Full time & $0(0.00)$ & & \\
\hline & Part time & $95(87.2)$ & & \\
\hline & Other & $14(12.8)$ & & \\
\hline Working minutes per week $(n=90)$ & & & $145.94 \pm 189.27$ & $90(30 \sim 1,500)$ \\
\hline \multirow[t]{4}{*}{ Financial compensation } & None & $9(8.3)$ & & \\
\hline & Regular monthly wage & $81(74.3)$ & & \\
\hline & Regular weekly wage & $4(3.7)$ & & \\
\hline & Payment by session & $15(13.8)$ & & \\
\hline $\begin{array}{l}\text { Compensation per session } \\
(1,000 \mathrm{KRW})(\mathrm{n}=100)\end{array}$ & & & $57.55 \pm 24.75$ & $50(10 \sim 150)$ \\
\hline Monthly income (n=101) & & & $270.54 \pm 180.32$ & $200(40 \sim 1,200)$ \\
\hline
\end{tabular}

*Participants gave multiple responses. 
200,000) (Table 3).

Music therapy was the most common type of therapy, accounting for $28.4 \%$ of all programs, followed by horticulture and art therapies (each accounting for $21.1 \%$ of programs), aromatherapy (13.8\%), tea ceremonies $(4.6 \%)$, crafting therapy $(3.7 \%)$, body movement/exercise therapy (2.8\%), and others (foot massages, calligraphy, reading therapy, meditation, and color therapies, each accounting for $0.9 \%$ of the total). The total number of therapies targeting patients only was $5.0 \%$, while $68 \%$ targeted patients and their family members and $27 \%$ targeted patients, family members, and hospice workers. The median number of sessions per month was 4 , the median duration of sessions was 60 minutes, and the median number of participants per session was 5. In most cases, social workers $(76.1 \%)$ were the main source of patient information that therapists used for improving the effectiveness of their therapy sessions. In total, $63.3 \%$ of therapists responded that they had very sufficient or somewhat sufficient information about patients, and $74.3 \%$ said they never attended team meetings, while $10.1 \%$ always attended. For support needed from medical professionals, $42.7 \%$ of therapists answered they needed support when it came to setting therapeutic goals, $29 \%$ when it came to responding to unexpected situations, and $19.4 \%$ when it came to symptom control so that patients could participate in therapy (Table 4).

Therapists rated their job satisfaction at 8.64 out of 10 on average, and $86.2 \%$ said they did not intend to get a new job. In addition, $43.1 \%$ participated in continuing education and training as part of efforts to improve their professional competencies, while $17.0 \%$ conducted research and $16.5 \%$ participated in clinical supervision programs (Table 4).

\section{Beliefs of hospice therapy managers and therapists about complementary therapy}

Managers and therapists agreed that complementary therapies are essential in hospice care, with average ratings of 8.88 points by managers and 9.33 points by therapists. For the impact of complementary therapy on patients, managers gave an average rating of 8.38 points, which is lower than the average rating of 8.90 points given by therapists. There was no significant difference between the ratings of managers and therapists for the impact of therapy on patients' family members, with average scores of 8.71 points among managers and 9.02 points among therapists (Table 5).

In total, $61.4 \%$ of managers and $59.1 \%$ of therapists agreed that complementary therapies helped provide psycho-emotional support for patients and family members. Managers believed that the therapies were helpful for patients and family members in restoring family relationships, restoring social functions, promoting spiritual well-being, palliating physical symptoms, and accepting death, in descending order, while therapists also believed therapies were helpful for family relationships, promoting spiritual well-being, palliating physical symptoms, accepting death, and restoring social functions, in descending order. Both managers and therapists agreed that expanding policy support at the government level, providing physical and environmental support for complementary therapies on the institutional level, and strengthening the competencies of therapists on the individual level were preconditions for improving the efficacy of complementary therapies in hospice care. Both groups also called for strengthening education and training programs for hospice therapists, standardizing therapy programs, improving public awareness of the need for complementary therapies, and managing and standardizing therapist qualifications, listed in descending order (Table 5).

\section{DISCUSSION}

Hospice palliative care provides integrated medical services with the purpose of offering comprehensive physical, psychosocial, and spiritual evaluations and treatment for terminal cancer patients. Due to the holistic and integrated characteristics of hospice palliative care services, complementary therapies play an important role. The National Hospice Center of the National Cancer Center also includes complementary therapy in their guide for providing hospice services [12]. While all 55 certified hospice care centers that participated in this study typically provided complementary therapies, 33 of them had temporarily stopped complementary therapy sessions according to COVID-19 pandemic guidelines restricting visitors. This suggests that complementary therapies are still considered low priority and that therapists are thought of as outsiders rather than full employees, as indicated by them being restricted from entering hospitals during the pandemic. 
Table 4. Therapists' Activities in Hospice ( $\mathrm{N}=109)$.

\begin{tabular}{|c|c|c|c|c|}
\hline Characteristics & Categories & $\mathrm{n}(\%)$ & Mean $\pm S D$ & Median (range) \\
\hline \multirow[t]{12}{*}{ Type of therapy } & Horticultural & $23(21.1)$ & & \\
\hline & Music & $31(28.4)$ & & \\
\hline & Art & $23(21.1)$ & & \\
\hline & Aroma & $15(13.8)$ & & \\
\hline & Tea ceremony & $5(4.6)$ & & \\
\hline & Handicraft & $4(3.7)$ & & \\
\hline & Body movement/exercise & $3(2.8)$ & & \\
\hline & Foot massage & $1(0.9)$ & & \\
\hline & Calligraphy & $1(0.9)$ & & \\
\hline & Reading & $1(0.9)$ & & \\
\hline & Meditation & $1(0.9)$ & & \\
\hline & Color & $1(0.9)$ & & \\
\hline \multirow[t]{4}{*}{ Target group (n=100) } & Patients & $5(5.0)$ & & \\
\hline & Patients and their families & $68(68.0)$ & & \\
\hline & Patient, their families, and hospice workers & $27(27.0)$ & & \\
\hline & Patients' families & $0(0.0)$ & & \\
\hline Monthly frequency of sessions & & & $4.61 \pm 2.56$ & $4(1 \sim 16)$ \\
\hline Minutes per session & & & $65.41 \pm 30.61$ & $60(10 \sim 240)$ \\
\hline Number of participants per session & & & $6.25 \pm 3.82$ & $5(1 \sim 20)$ \\
\hline \multirow[t]{5}{*}{ Resource for patient information } & Head nurse & $12(11.0)$ & & \\
\hline & Staff nurse & $3(2.8)$ & & \\
\hline & Social worker & $83(76.1)$ & & \\
\hline & Advanced practice nurse & $9(8.3)$ & & \\
\hline & Other & $2(1.8)$ & & \\
\hline \multirow[t]{5}{*}{ Adequacy of information } & Very sufficient & $25(22.9)$ & & \\
\hline & Somewhat sufficient & $44(40.4)$ & & \\
\hline & Neither sufficient nor insufficient & $34(31.2)$ & & \\
\hline & Somewhat insufficient & $6(5.5)$ & & \\
\hline & Very insufficient & $0(0.0)$ & & \\
\hline \multirow[t]{3}{*}{ Participation in team meetings } & Always & $11(10.1)$ & & \\
\hline & Occasionally & 17(15.6) & & \\
\hline & Never & $81(74.3)$ & & \\
\hline \multirow{5}{*}{$\begin{array}{l}\text { Support needed from medical } \\
\text { professionals* }\end{array}$} & Setting therapeutic goals & $53(42.7)$ & & \\
\hline & Symptom control for participation in therapy & $24(19.4)$ & & \\
\hline & Responding to unexpected situations & $36(29.0)$ & & \\
\hline & Evaluating effects of therapy & $9(7.3)$ & & \\
\hline & Grief support after patient death & $2(1.6)$ & & \\
\hline Job satisfaction ( $n=106)$ & & & $8.64 \pm 1.71$ & $9(3 \sim 10)$ \\
\hline \multirow[t]{3}{*}{ Intention to leave their job } & Yes & $5(4.6)$ & & \\
\hline & No & $94(86.2)$ & & \\
\hline & Don’tknow & $10(9.2)$ & & \\
\hline \multirow[t]{5}{*}{$\begin{array}{l}\text { Efforts to improve professional } \\
\text { competencies* }\end{array}$} & $\begin{array}{l}\text { Participating in continuing education and } \\
\text { training }\end{array}$ & $81(43.1)$ & & \\
\hline & Conducting research & $32(17.0)$ & & \\
\hline & $\begin{array}{l}\text { Participating in a clinical supervision } \\
\text { program }\end{array}$ & $31(16.5)$ & & \\
\hline & Attending hospice team meetings & $16(8.5)$ & & \\
\hline & Other & $28(14.9)$ & & \\
\hline
\end{tabular}

*Participants gave multiple responses. 
Table 5. Beliefs of Hospice Therapy Managers and Therapists Regarding Therapy in Hospice.

\begin{tabular}{|c|c|c|c|c|c|}
\hline \multirow{2}{*}{ Categories } & \multirow{2}{*}{ Items } & \multicolumn{2}{|c|}{$\mathrm{n}(\%)$ or mean $\pm \mathrm{SD}$} & \multirow{2}{*}{$\mathrm{t}$} & \multirow{2}{*}{$\mathrm{P}$} \\
\hline & & Managers ( $n=59)$ & Therapists ( $n=109$ ) & & \\
\hline \multicolumn{2}{|c|}{ Necessity of the therapy in hospice } & $8.88 \pm 1.66$ & $9.33 \pm 1.06$ & -1.89 & 0.064 \\
\hline \multicolumn{2}{|c|}{ Effects of therapy on patients } & $8.38 \pm 1.74$ & $8.90 \pm 1.34$ & -2.15 & 0.033 \\
\hline \multicolumn{2}{|c|}{ Effects of therapy on patients' families } & $8.71 \pm 1.55$ & $9.02 \pm 1.19$ & -1.47 & 0.145 \\
\hline \multirow{7}{*}{$\begin{array}{l}\text { The help that therapy } \\
\text { provides for patients and } \\
\text { their families* }\end{array}$} & Psycho-emotional support & $54(61.4)$ & $101(59.1)$ & & \\
\hline & Restoration of family relationships & $13(14.8)$ & $31(18.1)$ & & \\
\hline & Restoration of social functions & $6(6.8)$ & $5(2.9)$ & & \\
\hline & Promoting spiritual well-being & $6(6.8)$ & $17(9.9)$ & & \\
\hline & Palliating physical symptoms & $5(5.7)$ & $9(5.3)$ & & \\
\hline & Acceptance of death & $3(3.4)$ & $8(4.7)$ & & \\
\hline & Others & $1(1.1)$ & $2(1.7)$ & & \\
\hline \multirow{7}{*}{$\begin{array}{l}\text { How to improve the } \\
\text { efficacy of hospice } \\
\text { therapies* }\end{array}$} & Expanding policy supportat the government level & $30(17.9)$ & $74(22.7)$ & & \\
\hline & $\begin{array}{l}\text { Providing physical and environmental support for } \\
\text { complementary therapy from institutions }\end{array}$ & $29(17.3)$ & $68(20.9)$ & & \\
\hline & $\begin{array}{l}\text { Strengthening the individual expertise of } \\
\text { therapists }\end{array}$ & $28(16.7)$ & $53(16.3)$ & & \\
\hline & $\begin{array}{l}\text { Strengthening education and training programs } \\
\text { for hospice therapists }\end{array}$ & $27(16.1)$ & $47(14.4)$ & & \\
\hline & Standardizing complementarytherapies & $24(14.3)$ & $29(8.9)$ & & \\
\hline & $\begin{array}{l}\text { Improving public awareness of the need for } \\
\text { various therapies in hospice }\end{array}$ & $18(10.7)$ & $33(10.1)$ & & \\
\hline & $\begin{array}{l}\text { Managing and standardizing therapist } \\
\text { qualifications }\end{array}$ & $12(7.1)$ & $14(4.3)$ & & \\
\hline
\end{tabular}

*Participants gave multiple responses.

The results of this study showed that the most common type of complementary therapy in hospice care was horticulture therapy (81.4\%), followed by music therapy (79.7\%), art therapy (76.3\%), and aromatherapy (57.6\%). By comparison, $71.7 \%$ of home and hospice care providers in the US provided massage therapy, $69.0 \%$ provided support group services, $62.2 \%$ offered music therapy, $58.6 \%$ had pet therapy, and $52.7 \%$ provided relaxation therapy [13]. The reason why horticulture therapy is common in Korea is probably due to a greater cultural awareness of indoor horticulture compared to other countries where horticulture therapy is mainly performed outdoors, and because patients tend to prefer nature-friendly therapies [14]. Hospices also provided other types of therapies including tea ceremonies, crafting therapy, body movement/ exercise therapy, foot massages, calligraphy, cooking, reading therapy, laugh therapy, and color therapy. The results of this study showed that only $8.5 \%$ of participating institutions provided foot massage services, presumably because foot massages are usually provided by non-expert volunteers and thus not categorized as a complementary therapy. The huge variety of therapies offered is beneficial since different therapies can provide physical and psychological support for terminal cancer patients and their families. However, at the same time, having many different therapy options may act as a factor limiting the possibility for therapies to achieve their maximum effects, which may be better achieved by a more focused approach to complementary therapy. This practice can be compared to certain international practices in which individual facilities specialize in different types of therapies [12,13]. The biggest concern regarding the South Korean system is the one-sizefits-all approach to its management of therapies with varying treatment goals and theoretical bases that do not accurately reflect the specific characteristics of each therapy and the wants and needs of individuals. For instance, music therapy is managed under the same therapy programs as horticulture and aroma therapies, and the Health Insurance Review and Assessment Service does not oversee the implementation or estimate the insurance costs of each type of therapy separately 
[15]. To maximize the effects of complementary therapies, the current evaluation criteria should be updated to assess the specific outcomes of each type of therapy, such as the satisfaction of patients and their families, rather than simply checking the availability of therapy programs.

Hospice care providers that participated in this study provided an average of 3.67 different types of complementary therapy sessions at least once a week. Monthly frequencies and durations of therapies did not differ according to the type of therapy. In other words, therapy sessions were typically provided on 3 4 days of the week by different visiting therapists. Previous studies found that horticulture therapy sessions were typically held two or more times per week [14], music therapy sessions were typically provided in two or more consecutive sessions [16], and aromatherapy and reflexology were typically provided based on individual treatment plans established after regular observation and the formation of relationships [17]. In addition to the need to conduct a variety of different types of therapy sessions, strategic support is necessary so that complementary therapies can be effective at improving the quality of life of patients and their families. Thus, evidence-based guidelines should be established for each type of therapy and followed closely in terms of implementation.

In a study of hospice care facilities in the United States, $54 \%$ of hospice facilities hired full-time therapists, and onethird to half of hospice patients participated in at least one complementary therapy even though therapies were primarily funded from donations or conducted on a volunteer basis [12]. This study found that therapies mostly targeted patients and their family members regardless of the type of therapy, and the number of average attendees per session ranged from three people in body movement/exercise therapy sessions to eight in foot massages and aromatherapy sessions. This suggests that therapies are provided as group activities at certain times rather than as personalized independent activities targeted to individuals. As a result, patients with limited mobility and who are physically weak may find it challenging to attend such programs, and sessions may ultimately focus more on the needs of family members. Ideally, therapists should be able to work for hospice facilities on a full-time basis so that they can provide therapies at places that are convenient for patients when the patients need them.
None of the institutions that participated in this study employed full-time therapists. Therapists averaged fewer than 3 work hours (145 minutes) per week, and their average monthly wage was KRW 270,000 (KRW 50,000 per session). By comparison, job listings were found on websites used by international inpatient or in-home hospice service providers to hire full-time therapists. Although it is difficult to make a comparison between countries given the complexity of this issue, low compensation for therapists in Korea has always been a problem [18]. Despite poor financial compensation, therapists were very satisfied with their jobs and gave an average job satisfaction rating of 8.64 out of 10 points. Moreover, 86.2\% of therapists did not have any intention to leave their job. This indicates that therapists have an innate passion for their jobs and are motivated regardless of compensation. Managers and therapists alike responded that expanded policy support by the government was the top priority for improving the efficacy of complementary therapy programs in hospice care centers, in addition to institutions creating environments that are more conducive to complementary therapies, strengthening the individual expertise of therapists, and strengthening education and training programs for hospice therapists. Moving forward, a better work environment for therapists can be ensured by improving public awareness of the need for complementary therapies in hospice settings, establishing scientific foundations for therapists' qualifications, standardizing therapies, and increasing patient participation.

In this study, more than $50 \%$ of the therapists had a master's or doctorate degree, and $96 \%$ held certifications for the therapies they practiced. However, there were excessively many different existing training and certification programs for the same types of therapies conducted at different levels by different institutions, such as associations, academic societies, international institutions, continuing education institutions, and universities, so it was difficult to determine which certifications were credible and which were not. Moreover, fewer than $50 \%$ of therapists reported completing standard education for hospice palliative care professionals, likely because the current standardized education for hospice palliative care professionals is not specifically designed for therapists. Therefore, a new tailored program should be developed for hospice therapists.

In total, $63 \%$ of the therapists reported that they had suf- 
ficient patient information, but that they received patient information from social workers, head nurses, or staff nurses before starting sessions due to restrictions on who can access electronic medical records. Since accurate and sufficient information about patients is a key element for ensuring that setting goals, conducting interventions, and evaluating performance in therapies go smoothly, active communication between therapists and staff is needed before therapy sessions are conducted.

Both managers and therapists believed that complementary therapies were very necessary in hospice care and that they had a tremendous impact on patients and their families. Therapists appreciated the impact of complementary therapies on patients more than managers (9.02 points vs. 8.71 points). Most managers and therapists believed that complementary therapies helped alleviate emotional/psychological symptoms and restore family relationships, while relatively fewer believed that complementary therapies were helpful for alleviating physical symptoms or accepting death. Earlier studies have suggested that complementary therapies have particularly significant effects in terms of alleviating symptoms that were likely to decrease the quality of life of patients, including psychological stress such as depression and anxiety, cancer-related fatigue, and pain $[3,6,8,19]$. A study of a Canadian hospice palliative care unit reported positive outcomes for controlling pain, discomfort, stiffness, and tension after beginning a holistic treatment program that included aromatherapy, massages, and reiki [20]. These outcomes prove that therapies not only provide psychological support, but also contribute to relieving physical symptoms in practice. Since many Korean hospice care agencies focus on offering a variety of therapy programs, the effectiveness of such programs should be evaluated based on multidimensional performance indicators suited to the purposes and characteristics of different types of complementary therapies.

Finally, the following recommendations are suggested based on the results of this study. Above all, more efforts should be undertaken to improve public awareness of the necessity and value of complementary therapies in hospice care facilities that provide integrated, holistic care for terminal cancer patients and their families. To this end, research should be conducted to support the development and application of evidence-based guidelines for each different type of therapy. Standardization of therapist qualifications and education, improved employ- ment conditions for therapists, and policy support for evidence-based actions will also be necessary. This study focused on examining the status of complementary therapies currently conducted by Korean inpatient hospice care facilities and did not evaluate each therapy program based on the newest evidence or guidelines. Follow-up research is needed to verify the quality and effectiveness of each type of therapy provided by institutions.

\section{CONFLICT OF INTEREST}

No potential conflict of interest relevant to this article was reported.

\section{ORCID}

Sinyoung Kwon, https://orcid.org/0000-0001-8707-9281

Jihye Bak, https://orcid.org/0000-0001-9528-5077

So-Hi Kwon, https://orcid.org/0000-0002-5640-0463

\section{AUTHOR'S CONTRIBUTIONS}

Conception or design of the work: SK, SHK. Data collection: SK, JB. Data analysis and interpretation: SHK. Drafting the article: SK, SHK. Critical revision of the article: SHK. Final approval of the version to be published: SK, SHK.

\section{SUPPLEMENTARY MATERIALS}

Supplementary materials can be found via https://doi. org/10.14475/jhpc.2021.24.2.85. 


\section{REFERENCES}

1. National Hospice Center: The current status in hospice and palliative settings [Internet]. Seoul: National Cancer Center, National Hospice Center; c1000-2020 [cited 2020 Oct 25]. Available from: http://www.hospice.go.kr.

2. Ciemins EL, Brant J, Kersten D, Mullette E, Dickerson D. Why the interdisciplinary team approach works: insights from complexity science. J Palliat Med 2016;19:767-70.

3. Zeng YS, Wang C, Ward KE, Hume AL. Complementary and alternative medicine in hospice and palliative care: A systematic review. J Pain Symptom Manage 2018;56:781-94.e4.

4. Dain AS, Bradley EH, Hurzeler R, Aldridge MD. Massage, music, and art therapy in hospice: Results of a national survey. J Pain Symptom Manage 2015;49:1035-41.

5. Gallagher LM, Lagman R, Bates D, Edsall M, Eden P, Janaitis J, et al. Perceptions of family members of palliative medicine and hospice patients who experienced music therapy. Support Care Cancer 2017;25:1769-78.

6. Choi HJ, Hwang EY. A meta-analysis of the effect of music therapy in hospice and palliative care. KJMT2019;21:75-102.

7. Cedric L, Mathilde L, Marilene F. Art therapy among palliative cancer patients: aesthetic dimensions and impacts on symptoms. Palliat Support Care 2016;14:376-80.

8. Jiang XH, Chen XJ, Xie QQ, Feng YS, Chen S, Peng JS. Effects of art therapy in cancer care: A systematic review and meta analysis. Eur J Cancer Care (Engl) 2020;29;e13277.

9. Lai CK, Lau CK, Kan WY, Lam WM Mbbs Mrcp Fhkcp Fhkam, Fung CYY Rsw Htr. The effect of horticultural therapy on the quality of life of palliative care patients. J Psychosoc Oncol 2017;35:278-91.

10. Yoo MS. Effects of aroma hand massage on state anxiety, depression, quality of sleep, and blood pressure of palliative patients in hospice. J Korean Acad Soc Home Care Nurs 2019;26:309-18.

11. Korean Ministry of Health and Welfare. 2019 Quality assessment indicators for certified hospice agencies. Appendix 1. Seajong:Korean Ministry of Health and Welfare;2019.p7.

12. National Cancer Center, National Hospice Center. Guide to the provision of hospice services. 5th ed. Goyang:National Cancer Center, National Hospice Center; 2020. p 17, 52-3, 91-2.

13. Bercovitz A, Sengupta M, Jones A, Harris-Koje LD. Complementary and alternative therapies in hospice: The national home and hospice care survey: United States, 2007. National Health Statistics Reports [Internet]. 2011;33;1-20. [cited 2020 Oct 10]. Available from:https:// stacks.cdc.gov/view/cdc/13195.

14. Soderback I, Soderstrom M, Schalander E. Horticultural therapy: the 'healing garden'and gardening in rehabilitation measures at Danderyd Hospital Rehabilitation Clinic, Sweden. Pediatr Rehabil 2004;7:245-60.

15. Kim EJ. Hospice music therapy in Korea. Korean J Hosp Palliat Care 2018;21:109-14.

16. Gao Y, Wei Y, Yang W, Jiang L, Li X, Ding J, et al. The effectiveness of music therapy for terminally ill patients: a meta-analysis and systematic review. J Pain Symptom Manage 2019;57:319-29.

17. Candy B, Armstrong M, Flemming K, Kupeli N, Stone P, Vickerstaff V, et al. The effectiveness of aromatherapy, massage and reflexology in people with palliative care needs: a systematic review. Palliat Med2020;34:179-94.

18. Kim EJ, Choi YS, Kim WC, Kim KS. The current status of music therapy centered on 54 hospice and palliative care settings designated by the Ministry of Health and Welfare in 2014. JMHB2016;13:19-40.

19. Kraft K. CAM for depression, anxiety, grief, and other symptoms in palliative care. Prog Palliat Care 2012;20:272-7.

20. Berger L, Tavares M, Berger B. A Canadian experience of integrating complementary therapy in a hospital palliative care unit. J Palliat Med 2013;16:1294-8. 